03

\title{
Детонация горючего газового цилиндра при фокусировке падающей ударной волны
}

\author{
() П.Ю. Георгиевский, В.А. Левин, О.Г. Сутырин \\ Научно-исследовательский институт механики Московского государственного университета им. М.В. Ломоносова, \\ Москва, Россия \\ ฯE-mail: sutyrin@imec.msu.ru
}

Поступило в Редакцию 28 августа 2019г.

В окончательной редакции 28 августа 2019г.

Принято к публикации 30 августа 2019г.

На основе уравнений Эйлера численно исследуется двумерное взаимодействие ударной волны в воздухе с эллиптической областью (двумерным газовым пузырем), заполненной пропан-кислородной смесью с примесью тяжелого газа. Горение пропана моделируется одностадийной аррениусовской кинетикой. Обнаружены три различных режима воспламенения: прямое инициирование детонации достаточно сильной волной, детонация вблизи тройной точки при преломлении менее интенсивной волны и детонация в области фокусировки еще более слабой волны. Последний режим наблюдается только для существенно вытянутых пузырей. Определена зависимость режима инициирования детонации от числа Маха волны и отношения диаметров пузыря. Показано, что за счет удлинения пузыря критическое число Маха может быть существенно снижено по сравнению со случаем прямого инициирования.

Ключевые слова: ударная волна, газовый пузырь, фокусировка, кумуляция, газовая детонация, воспламенение.

DOI: 10.21883/PJTF.2019.23.48719.18022

Взаимодействие ударных волн с локальными неоднородностями имеет место во многих течениях: от космических процессов со сверхновыми звездами до систем высокоскоростного сгорания и инерционного термоядерного синтеза. Такие течения часто исследуются на основе задачи о взаимодействии ударной волны с газовым пузырем (shock-bubble interaction, $\mathrm{SBI}$, в том числе химически реагирующим (RSBI), включающей широкий спектр ударно-волновых эффектов, типов неустойчивостей и видов волн реакции. Начиная с первых экспериментов [1] эта задача активно исследуется в последние годы. В недавнем цикле численных исследований [2-4] было обнаружено существенное влияние начального давления смеси и интенсивности падающей волны на тип воспламенения пузыря: дефлаграцию или детонацию, а также существенное уменьшение интенсивности перемешивания газов в результате воздействия волны реакции.

Известно несколько ключевых явлений, сопутствующих взаимодействию ударной волны с газовым пузырем: неоднородное ускорение и деформация пузыря, генерация завихренности, турбулентное перемешивание газов и фокусировка поперечных скачков уплотнения. Последний эффект представляет особый интерес в связи с инициированием горения газовых смесей и поэтому также активно исследуется в настоящее время. Известно, что все основные параметры задачи (интенсивность падающей волны, плотность газа в пузыре и его форма) играют важную роль при определении режима преломления волны и интенсивности фокусировки [5]. В общем случае для плотных и вытянутых пузырей реализуется более интенсивный внутренний режим преломления (type I [6]), при котором фокусировка поперечных скачков более интенсивна, чем во внешнем режиме (type II), и, что не менее важно, пиковые значения давления и температуры газа достигаются внутри пузыря. Аналогичный эффект наблюдается при взаимодействии ударной волны с локальным облаком мелкодисперсной пыли [7].

Опираясь на эти данные, можно предположить, что форма пузыря будет играть важную роль и при воспламенении горючей смеси за счет преломления и фокусировки падающей волны. В настоящей работе численно исследуется взаимодействие ударной волны с эллиптическим реагирующим газовым пузырем в двумерной плоской постановке.

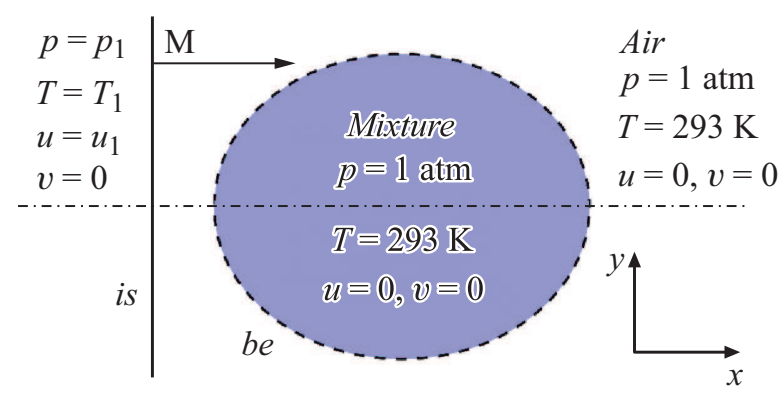

Рис. 1. Схема начальных условий: $i s-$ исходная ударная волна, $b e-$ граница пузыря (газового цилиндра). Штрихпунктирной линией отмечена плоскость симметрии задачи. 
$a$
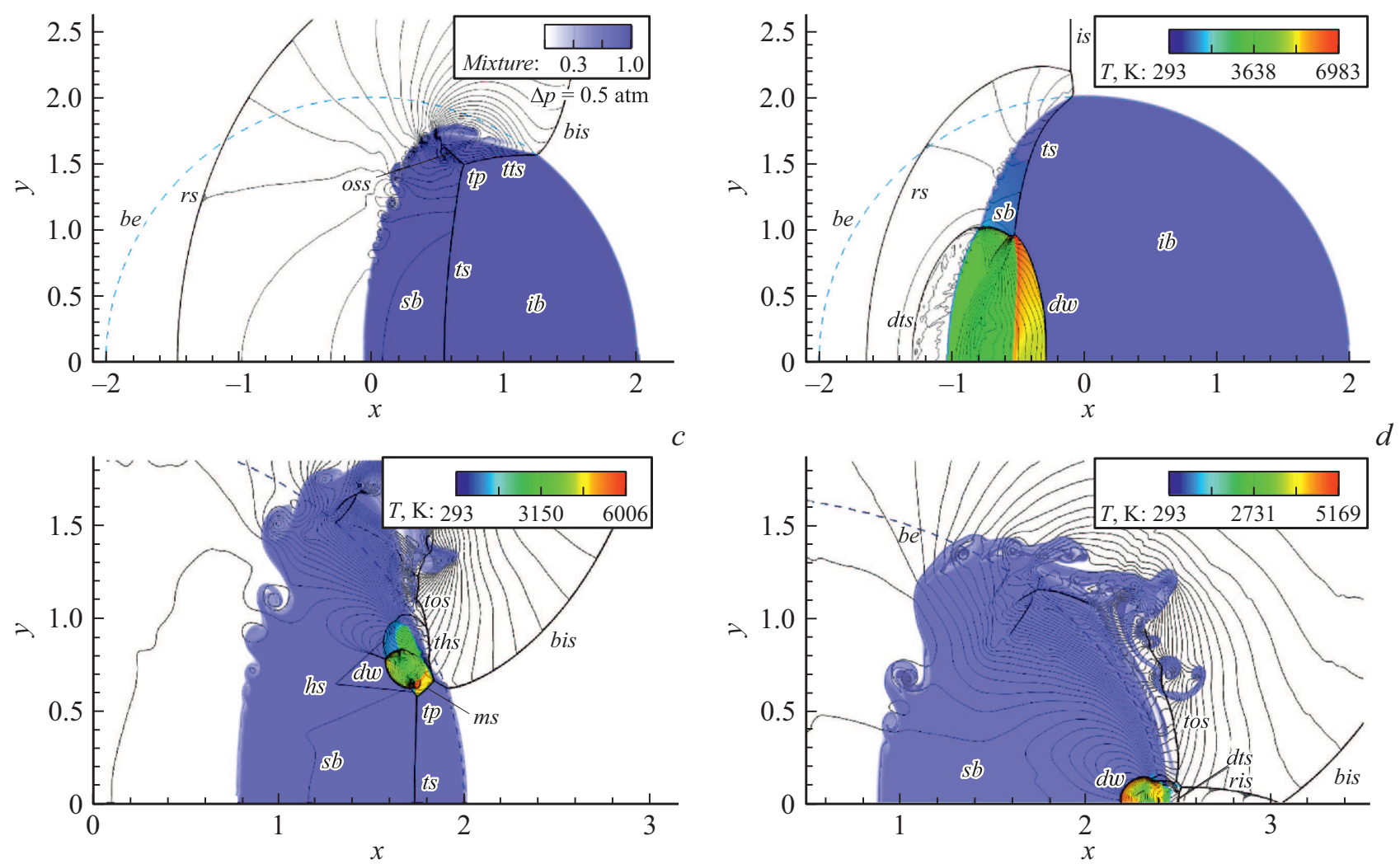

Рис. 2. Преломление ударной волны $(a)$ и различные режимы инициирования детонации газовой смеси: прямой при $\mathrm{M}=3.4(b)$; при преломлении волны, $\mathrm{M}=3.0(c)$; при фокусировке волны, $\mathrm{M}=2.7, \eta=1.44(d)$. Представлена верхняя половина течения, приведены изолинии давления, цветом (или градациями серого в печатной версии статьи) показана массовая доля горючей смеси и температура газа (только значения $T>1100 \mathrm{~K}) ; i b, s b-$ невозмущенная и ударно-сжатая части пузыря; bis - выпуклая часть падающей волны; $r s, t s$ - отраженный и прошедший скачки; $t t s$, oss - поперечные вторичные скачки; $t p$ - тройная точка; $d w$ - детонационная волна; $m s$ - ножка Маха; $h s$ - индуцированные тепловыделением скачки; ris - отраженный от плоскости симметрии скачок bis; dts - вызванная детонацией ударная волна в воздухе; tos, ths — вышедшие в воздух волны oss и $h s$ соответственно.

Нестационарные течения смеси совершенных газов моделируются с помощью уравнений Эйлера

$$
\frac{\partial}{\partial t}\left(\begin{array}{c}
\rho_{i} \\
\rho u \\
\rho v \\
H-p
\end{array}\right)+\frac{\partial}{\partial x}\left(\begin{array}{c}
\rho_{i} u \\
p+\rho u^{2} \\
\rho u v \\
H u
\end{array}\right)+\frac{\partial}{\partial y}\left(\begin{array}{c}
\rho_{i} v \\
\rho u v \\
p+\rho v^{2} \\
H v
\end{array}\right)=0
$$

где $\rho_{i}$ - плотности газовых компонентов, $\rho=\sum \rho_{i}-$ общая плотность смеси, $u, v$ - компоненты скорости газа вдоль декартовых осей $x, y$ соответственно, а давление $p$ и полная энтальпия единицы объема газа $H$ вычисляются следующим образом:

$$
p=\sum \rho_{i} \frac{R}{\mu_{i}} T, \quad H=\sum \rho_{i}\left(c_{p i} T+h_{0 i}\right) .
$$

Здесь $T$ - абсолютная температура, $R$ - универсальная газовая постоянная, а $\mu_{i}, c_{p i}, h_{0 i}-$ молярные массы, удельные теплоемкости и энтальпии образования компонентов.

Термодинамические параметры шести используемых газовых компонентов $\left(\mathrm{C}_{3} \mathrm{H}_{8}, \mathrm{O}_{2}, \mathrm{~N}_{2}, \mathrm{CO}_{2}, \mathrm{H}_{2} \mathrm{O}, \mathrm{Xe}\right)$ приведены в [8]. Реакция горения пропана моделируется одностадийной аррениусовской кинетикой Westbrook-Dryer [9].

Для численного моделирования применяется метод конечных объемов типа „MUSCLE“ с линейной реконструкцией величин на границах расчетных ячеек, ограничителем ван Лира и HLLC-методом решения задачи о распаде разрыва, обеспечивающий второй порядок аппроксимации решения по времени и пространству. Используется равномерная квадратная расчетная сетка со стороной ячейки в $12 \mu \mathrm{m}$, обеспечивающая 5-6 ячеек на зону реакции в детонационной волне.

На рис. 1 приведены начальные условия задачи. Ударная волна распространяется слева направо по покоящемуся воздуху (одна часть $\mathrm{O}_{2}$, четыре части $\mathrm{N}_{2}$ по объему) в нормальных условиях, содержащему эллиптическую область, заполненную стехиометрической горючей газовой смесью (одна часть $\mathrm{C}_{3} \mathrm{H}_{8}$, пять частей $\mathrm{O}_{2}$, пять частей $\mathrm{N}_{2}$, пятнадцать частей Хе по объему). Плотность смеси превышает плотность окружающего 




Рис. 3. Зависимость режима воспламенения от числа Маха М и отношения диаметров пузыря $\eta$. Каждый символ соответствует одному расчету, некоторые промежуточные значения опущены. 1 - нет детонации, 2 - прямое инициирование, 3 - детонация при преломлении, 4 - при фокусировке.

воздуха в 3.1 раза, что обеспечивает достижимость внутреннего режима фокусировки волны [5]. Однородное состояние воздуха за волной определяется числом Маха М с помощью соотношений Ренкина-Гюгонио. Геометрия сечения цилиндра задается отношением диаметров эллипса $\eta=d_{x} / d_{y}$, при этом площадь сечения постоянна и равна $12.6 \mathrm{~cm}^{2}$, что соответствует круглому цилиндру $(\eta=1)$ диаметром $4 \mathrm{~cm}$.

За счет отставания ударной волны $t s$ (рис. 2,a), прошедшей в пузырь, от наружной волны is внутри пузыря формируются поперечные скачки уплотнения $t t s$, oss и тройная точка $t p$, движущиеся по диагонали к плоскости симметрии течения. В зависимости от параметров течения тройная точка $t p$ и скачок $t t s$ достигают плоскости снаружи или внутри пузыря $[5,6]$, при этом наблюдается резкое повышение давления и температуры газа в локальной области. Опираясь на эти данные, можно ожидать, что существует как минимум три различных режима детонационного воспламенения пузыря: прямое инициирование детонации смеси достаточно сильной волной, воспламенение вблизи тройной точки $t p$ при меньшем числе Маха волны и воспламенение в области фокусировки еще более слабой волны.

В проведенных расчетах прямое инициирование детонации наблюдается при $\mathrm{M} \geqslant 3.2$. Детонационная волна $d w$ (рис. $2, b$ ) формируется у левого края пузыря вскоре после прохождения волны в смесь, затем обгоняет волну $t s$ и распространяется далее в режиме Чепмена-Жуге, полностью поглощая реагирующую смесь. При этом фронт детонационной волны имеет характерную ячеистую структуру с шириной ячейки около $0.5 \mathrm{~mm}$.

При меньших числах Маха температура за прошедшей волной $t s$ недостаточна для прямого воспламенения смеси. В процессе преломления волны формируется зона интенсивного тепловыделения вблизи тройной точки $t p$, индуцирующая скачки $h s$ и $t h s$, распространяющиеся по смеси и по воздуху снаружи пузыря соответственно. При взаимодействии скачка $h s$ с вторичным скачком внутри пузыря формируется самоподдерживающаяся де- тонационная волна $d w$ (рис. $2, c)$, которая затем проходит по всему деформированному пузырю.

Для еще более слабых волн $(\mathrm{M} \leqslant 2.9)$ тепловыделение вблизи тройной точки недостаточно, и детонации для круглых пузырей не наблюдается. Однако для вытянутых пузырей $(\eta>1)$ инициируется детонация за счет фокусировки поперечных скачков и тройных точек в горючей смеси вблизи правого полюса пузыря (рис. 2,d).

На основе проведенного параметрического исследования для $2.0 \leqslant \mathrm{M} \leqslant 3.5$ и $0.5 \leqslant \eta \leqslant 2.0$ можно качественно оценить зависимость режима инициирования детонации от этих параметров (рис. 3). Для сплюснутых пузырей $(\eta=0.5)$ наблюдается только прямое инициирование при $\mathrm{M} \geqslant 3.2$. С увеличением $\eta$ появляются непрямые режимы инициирования: сначала вблизи тройной точки при $\eta=0.7$, а затем и при фокусировке скачков при $\eta=1.44$. Критическое число Маха, достаточное для детонации, при этом уменьшается примерно на $35 \%$ : $\mathrm{c} \mathrm{M}=3.2$ до 2.4. При дальнейшем удлинении пузыря существенных изменений не наблюдается.

На основе численного моделирования взаимодействия ударной волны с эллиптической областью (пузырем) горючей газовой смеси показано, что режим инициирования детонации смеси и критическая интенсивность падающей волны существенно зависят от формы пузыря. Примененная модель не включает эффекты вязкости, теплопроводности и диффузии, а также не учитывает времени индукции реакции горения, поэтому границы областей параметров, соответствующих конкретным режимам воспламенения, определены лишь приблизительно. Однако с большой долей вероятности можно считать, что основной эффект - существенное снижение критического числа Маха при удлинении пузыря - имеет под собой реальную основу. Этот эффект, в частности, может быть использован для повышения эффективности прямоточных высокоскоростных систем сгорания с инициированием горения за счет взаимодействия струи топливной смеси со стационарной косой ударной волной.

\section{Финансирование работы}

Работа выполнена в НИИ механики МГУ им. М.В. Ломоносова с использованием оборудования Центра коллективного пользования сверхвысокопроизводительными вычислительными ресурсами МГУ при частичной финансовой поддержке Совета по грантам Президента РФ (МК-3012.2019.1) и Российского фонда фундаментальных исследований (проект № 18-01-00793).

\section{Конфликт интересов}

Авторы заявляют, что у них нет конфликта интересов. 


\section{Список литературы}

[1] Haehn N., Ranjan D., Weber C., Oakley J., Rothamer D., Bonazza R. // Combust. Flame. 2012. V. 159. N 3. P. 1339 1350.

[2] Diegelmann F., Tritschler V., Hickel S., Adams N. // Combust. Flame. 2016. V. 163. P. 414-426.

[3] Diegelmann F., Hickel S., Adams N. // Combust. Flame. 2016. V. 174. P. 85-99.

[4] Diegelmann F., Hickel S., Adams N. // Combust. Flame. 2017. V. 181. P. $300-314$.

[5] Georgievskiy P.Yu., Levin V.A., Sutyrin O.G. // Shock Waves. 2015. V. 25. N 4. P. 357-369.

[6] Ray J., Samtaney R., Zabusky N. // Phys. Fluids. 2000. V. 12. N 3. P. 707-716.

[7] Георгиевский П.Ю., Левин В.А., Сутырин О.Г. // Письма в ЖТФ. 2016. Т. 42. В. 18. С. 17-24.

[8] TRC Thermodynamic Tables. Thermodynamic Research Center Texas, A\&M University, College Station, TX, 1998.

[9] Westbrook C., Dryer F. // Prog. Energy Combust. Sci. 1984. V. 10. N 1. P. 1-57. 